Principal Research Engineer

\section{Micro and}

Nanotechnology Laboratory

\section{College of Engineering}

University of Illinois

at Urbana-Champaign

The Micro and Nanotechnology Laboratory at the College of Engineering seeks applicants for the position of Principal Research Engineer. Reporting to the Director, the Principal Research Engineer will provide leadership within multiple laboratory environments within MNTL for operation/ maintenance of research equipment, development/ implementation of safety policies, and student/staff training. Please visit http://jobs.illinois.edu to view the complete position announcement and application instructions. The closing date for this position is

February 29, 2016

The University of Illinois conducts criminal background checks on all job candidates upon acceptance of a contingent offer.

Illinois is an

EEO Employer/Vet/Disabled www.inclusiveillinois.illinois.edu

\section{ILLINOIS}

\section{ASSISTANT/ASSOCIATE PROFESSOR}

\section{Department of Polymer Engineering}

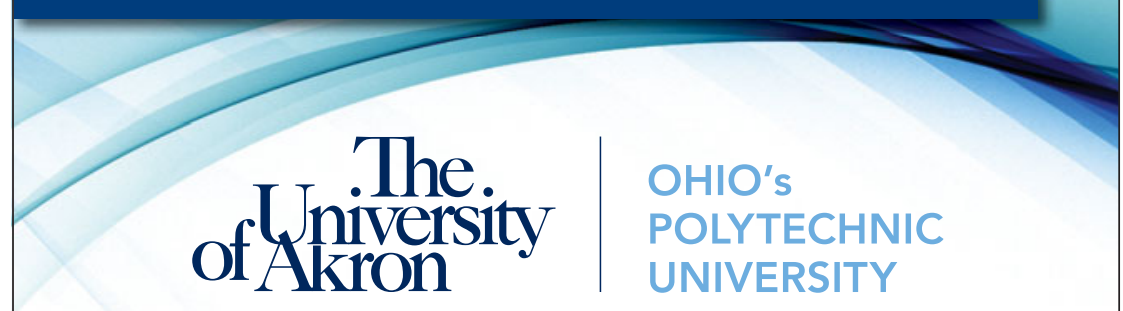

The Department of Polymer Engineering at The University of Akron is seeking applications for TWO (2) TENURE-TRACK ASSISTANT OR ASSOCIATE PROFESSOR POSITIONS with research interests respectively in polymer processing and polymer rheology.

For the POLYMER PROCESSING POSITION, research interests in modeling of polymer processing such as extrusion, microinjection molding, and thermoforming, advanced manufacturing processes such as additive manufacturing, roll to roll manufacturing processes and associated metrology tools needed for emerging technologies including flexible electronics, and processing-structure-property relationships, or related areas are desired. Applicants should have an earned $\mathrm{PhD}$ degree in engineering or a related discipline with a minimum of two years of industrial experience or postdoctoral experience in academic and/or industrial setting and demonstrated research interests in polymer processing. Applicants with three to four years of experience in an equivalent academic department, in industry, or during postdoctoral research in academic and/or industrial setting will be given favorable consideration. For the POLYMER RHEOLOGY POSITION, applicants should have an earned $\mathrm{PhD}$ degree in polymer engineering, chemical engineering, mechanical engineering, materials science, physics, or a related discipline and demonstrated active research interests and experience in polymer rheology.

Applicants with demonstrated post-graduation experience in an equivalent academic department, in industry, or during postdoctoral research in academic and/or industrial setting will be given favorable consideration, however, these may be waived for exceptional candidates. Prior research experience in experimental and/or computational rheology of polymers and complex fluids including rheological aspects of polymeric microfluidics and biopolymeric systems is highly desirable.

In addition to establishing a strong, externally funded research program, the successful applicants will be expected to direct graduate student research, teach graduate and undergraduate classes, and contribute to the functioning of the department, college, and university through service on committees and participation in departmental activities. The University of Akron, with more than 25,000 students, has a world class program in polymer science and polymer engineering with a long history in polymers dating back to 1909. The Department of Polymer Engineering currently has 13 full time faculty and 149 full time and part time graduate students.

For complete details and to apply, please visit www.uakron.edu/jobs, Job Nos. 9282 and 9288. (An application must be submitted per job number.)

Be prepared to upload a cover letter, curriculum vitae with list of publications, documentation of prior research support (if applicable), detailed research and teaching plans, and the names and contact information of at least three professional references.

The University of Akron is an equal education and employment institution. It is the policy of this institution that there shall be no unlawful discrimination against any individual in employment or in its programs or activities at The University of Akron because of race, color, religion, sex, age, national or ethnic origin, sexual orientation, gender identity, disability, genetic information, or status as a veteran. The University is also committed to the principles of affirmative action and acts in accordance with state and federal laws 